\title{
RESEARCH
}

Open Access

\section{Estimating the creep behavior of glass- fiber-reinforced polyamide considering the effects of crystallinity and fiber volume fraction}

${\text { Takenobu Sakai }{ }^{1 *} \text {, Y Yuto Hirai }}^{2}$ and Satoshi Somiya ${ }^{2}$

\begin{abstract}
Background: The time-temperature superposition principle (TTSP) is often used to estimate the viscoelastic behavior of polymers. It can also be used to evaluate the influence of a given variable, or set of variables, on viscoelastic properties. In this research, the effects of time, temperature, fiber volume fraction and the relative crystallinity of polyamide (PA) and glass fiber-reinforced polyamide (GFRPA) were investigated using the timetemperature superposition principle to estimate viscoelastic behavior under each set of conditions.

Methods: The crystallinities of PA and GFRPA, which ranged from 33 to 45\%, were controlled by adjusting the duration of crystallization as $250^{\circ} \mathrm{C}$. Creep tests were carried out with these materials, and creep compliance curves of each condition were obtained.

Results: Using these creep compliance curves, the master curves for temperature, and the grand master curves for crystallinity and for fiber volume fraction were generated to show the relationships between fiber volume fraction, crystallinity, and viscoelastic parameters. Furthermore, the great-grand master curve for crystallinity and fiber volume fraction was generated to predict creep behavior in an arbitrarily condition. The predicted data were in good agreement with experimental results.

Conclusions: A method for estimating creep deformation taking into account the effects of influencing variables was developed. The time-temperature superposition principle (TTSP) was applied to the effects of the fiber volume fraction and crystallinity. Grand master curves for crystallinity and fiber volume fraction were obtained by shifting the corresponding master curves. This study demonstrates that the creep behaviors of fiber-reinforced plastics can be estimated using these shift factors and a great-grand master curve. This method yielded estimates of creep deformation that fitted well with experimental results. Based on our findings, it should be possible to control creep deformation in plastics or fiber-reinforced resins by controlling the fiber volume fraction and the crystallinity of the matrix material.
\end{abstract}

Keywords: Creep, Time temperature superposition principle, Crystallinity, Glass Fiber-reinforced plastics, Polyamide

\footnotetext{
* Correspondence: sakai@mech.saitama-u.ac.jp

${ }^{1}$ Graduate School of Science and Engineering, Saitama University, 255

Shimo-Okubo, Sakura-ku, Saitama-shi, Saitama 338-8570, Japan

Full list of author information is available at the end of the article
} 


\section{Introduction}

Time-dependent materials such as polymers and their composites are used in several important structural materials, particularly in the aerospace and automotive industries. These materials have viscoelastic properties that are a function of their time-dependent material properties (Ferry 1950; Schwarzl and Staverman 1952; Schapery 1969; Schapery 1997; Lou and Schapery 1971). When using time-dependent materials in the design of structural elements, it is important to know how their mechanical properties can change during the useful life of the product. The degree of change in a polymeric material's mechanical properties depends on many variables, including pressure, temperature, humidity, crystallinity, and, in composites, the fiber volume fraction. Therefore, these variables should be considered when estimating long-term durability and must be understood to fully predict and understand creep behavior.

Polyamide (PA) resin boasts excellent mechanical properties, including high specific strength and moduli, but also exhibits excellent moldability. PA and fiber-reinforced plastics (FRPs) based on PA are used throughout the field of mechanical engineering. It is therefore important to understand their time-dependent mechanical properties and their long-term behavior. The time-temperature superposition principle (TTSP) is generally used to estimate the mechanical properties and long-term behavior of polymers (Nakada et al. 2011; Cai et al. 2013; Giannopoulos and Burgoyne 2012; Oseli et al. 2016; Creus 2015). The effects of crystallinity on creep behavior have also been investigated by applying the TTSP (Chen 1998; Chiang and Lo 1987; Sukhanova et al. 2004).

In previous studies, Sakai and Somiya (2006, 2009, 2011, 2012), Sakai et al. (2007, 2011a, 2011b, 2015) and Tanks et al. (2016) investigated the relationships between creep behavior, crystallinity, and the fiber volume fraction of a variety of polymers. The effects of these variables are described by shift factors that can be used to generate time-temperature curves at any given percent crystallinity or fiber volume fraction. Crystallinity and fiber volume fraction have similar effects on creep behavior. In a crystalline polymer, creep behavior depends on the nature of the amorphous regions and the shape of the crystalline domains. In FRPs, the properties of the matrix resin have a dominant influence on creep behavior. The effect of crystallinity and fiber volume fraction on the creep behavior have been separately investigated by authors. Here, the amorphous resin has a dominant influence on creep behavior of both effects, therefore, the relationship both effects can be found. In this study, the relationship between the effect of crystallinity and volume fraction was investigated. Using the TTSP, we estimated long-term creep behaviors taking into account the degrees of influence imparted by the relative crystallinity of the polymer and the fiber volume fractions of corresponding FRPs.

\section{Experimental}

Linear viscoelastic theory

Creep deformation was evaluated according to viscoelastic theory using the creep compliance function $D_{\mathrm{C}}(t)$. This value is based on the linear viscoelastic equation for creep strain as follows,

$$
\in(t)=\int_{0}^{t} D_{C}(t-\tau, T) \frac{d \sigma}{d \tau} d \tau
$$

where $\epsilon(t)$ shows the temporal response of the amount of creep strain, and $D_{\mathrm{C}}(t, T)$ shows the temporal response of the creep compliance at temperature $T$ under the influence of an external force.

To calculate creep deformation based on viscoelastic theory, it is necessary to determine $D_{C}(t)$, which can range from several seconds to several years under all temperature conditions, making it difficult to carry out long-term tests. The TTPS simulates accelerated aging to make long-term predictions of polymer behavior. Curves generated through the TTPS can be used to describe long-term creep behavior. Master curves are created by superpositioning multiple curves acquired at different settings of a given variable. For example, to produce a master curve of creep compliance, creep compliance curves acquired at various temperatures are shifted horizontally until they completely overlap the curve at a reference temperature. The shift factors required to superposition each curve can be assembled into a retardation time spectrum that describes the predicted viscoelastic properties of the material. In this study, we performed creep analyses under the assumption that the TTSP could be applied to determine the influence of variables other than temperature.

\section{Materials and experimental procedure}

PA (PA66: LEONA1300S, $T_{\mathrm{g}}=50{ }^{\circ} \mathrm{C}$ ) and GFRPA (13G15, 1300G) were acquired from Asahikasei Co. Ltd., (Japan). The weight fractions (volume fractions) of glass fiber in the test specimens were $0 \%(0 \%), 15 \%(7 \%)$ and $33 \%(15 \%)$ and are denoted hereafter as G0, G7 and G15, respectively. The FRP boards were injection molded as the dimension of $200 \times 200 \times 2.5 \mathrm{~mm}$. Specimens were cut from these boards. Specimens measured $60 \times 10 \times 2.5 \mathrm{~mm}$. It has been reported that the crystallinity of these materials can be adjusted by controlling the temperature and duration of heat treatment (Chen 1998; Chiang and Lo 1987; Sukhanova et al. 2004). In 
this study, the crystallinities of PA and GFRPA were adjusted by changing the duration of heat treatments between 0 to $10 \mathrm{~h}$. A thermal history of heat treatments is shown in Fig. 1. Briefly, PA and GFRPA were dried at $90{ }^{\circ} \mathrm{C}$ for $6 \mathrm{~h}$. After drying, the materials were annealed at $250{ }^{\circ} \mathrm{C}$ for 0.2 to $40 \mathrm{~h}$ to obtain a specified degree of crystallinity. To determine the best temperature for these heat treatments, DSC analyses were carried out at $220{ }^{\circ} \mathrm{C}$ and $250{ }^{\circ} \mathrm{C}$. The conditions of DSC analysis was that the test temperature was increased until it reach to $300{ }^{\circ} \mathrm{C}$ with $10{ }^{\circ} \mathrm{C} / \mathrm{min}$, and it kept for 5 min with $\mathrm{N}_{2}$ gas $(5 \mathrm{ml} / \mathrm{min})$. Figure 2 shows thermograms of as-received PA that had been heat treated at $220{ }^{\circ} \mathrm{C}$ or $250{ }^{\circ} \mathrm{C}$. Crystallinity could be controlled to $\mathrm{X}=40 \%$ via heat treatment at $220{ }^{\circ} \mathrm{C}$ for $40 \mathrm{~h}$ or at $250{ }^{\circ} \mathrm{C}$ for $5 \mathrm{~h}$. Thermograms of PA that been annealed at $220{ }^{\circ} \mathrm{C}$ or $250{ }^{\circ} \mathrm{C}$ exhibited significantly different endothermic reactions around the melting point. The thermogram of PA that had been annealed at $220{ }^{\circ} \mathrm{C}$ contained two endothermic peaks around $245{ }^{\circ} \mathrm{C}$ and $265{ }^{\circ} \mathrm{C}$, which correspond to the gradation of different crystals that had been generated by extended baking at $220{ }^{\circ} \mathrm{C}$ (Chiang and Lo 1987) and the melting point, respectively. These data suggest that PA adopts two crystal structures during heating at $220^{\circ} \mathrm{C}$. In contrast, the thermogram of PA that had been baked at $250{ }^{\circ} \mathrm{C}$ contained only a single endothermic peak corresponding to the melting point. This suggests that subjecting PA to shorter-term baking at $250{ }^{\circ} \mathrm{C}$ results in a single crystal structure. Therefore, to reduce the number of variables being evaluated, we chose to use PA and GFRPA that had been heat-treated at $250{ }^{\circ} \mathrm{C}$. This yielded PA and GFRPA with crystallinities of $\sim 32 \%$ to $\sim 50 \%$, as shown in Fig. 3 .

Densimetry tests, using the water substitution method and an AX-120 analytical balance (SHIMADZU, Co., Ltd.,), were performed to determine the crystallinity of our materials as shown in Eq. 2.

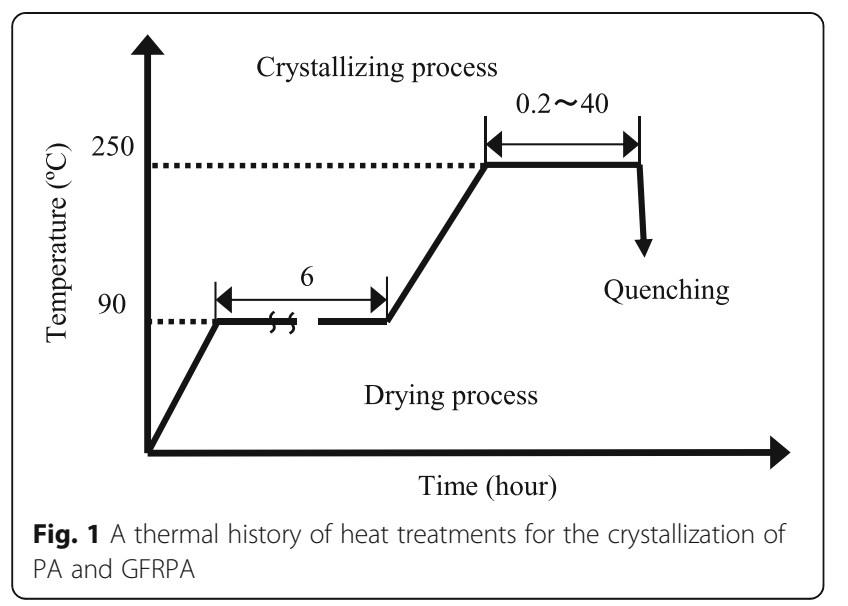

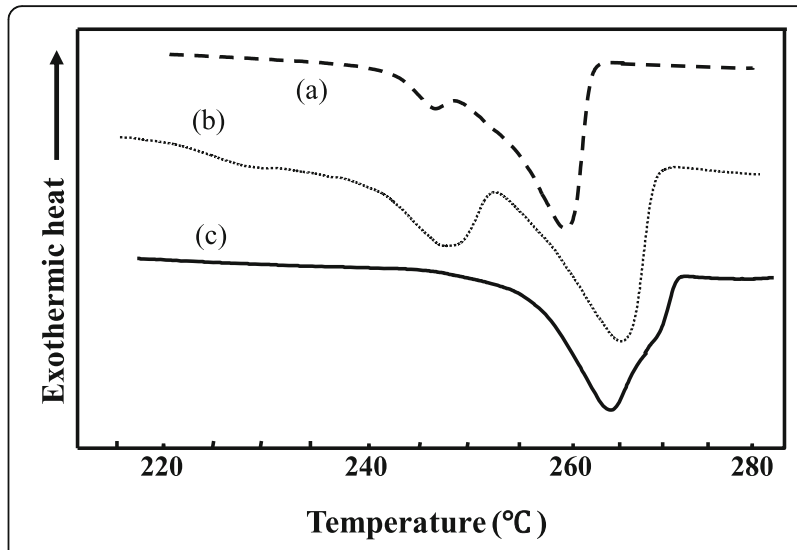

Fig. 2 DSC thermograms of PA: (a) as-received, $x=32 \%$, (b) heated at $220^{\circ} \mathrm{C}$ for $40 \mathrm{~h}, \mathrm{x}=40 \%$ and (c) heated at $250^{\circ} \mathrm{C}$ for $5 \mathrm{~h}, \mathrm{x}=40 \%$

$$
x=\frac{d_{c}\left(d_{m}-d_{a}\right)}{d_{m}\left(d_{c}-d_{a}\right)}
$$

$x$ : Crystallinity (\%).

$d_{C}$ : Crystalline density $\left(1.24 \mathrm{~kg} / \mathrm{m}^{3}\right)$ (Brandrup et al. 2003)

$d_{a}$ : Amorphous density $\left(1.07 \mathrm{~kg} / \mathrm{m}^{3}\right)$ (Brandrup et al. 2003)

$d_{m}$ : Material (matrix) density $\left(\mathrm{kg} / \mathrm{m}^{3}\right)$

In the case of GFRPA, the density of the resin was calculated from the density of the composite using Eq. (3).

$$
d=d_{f} V_{f}+d_{m} V_{m}
$$

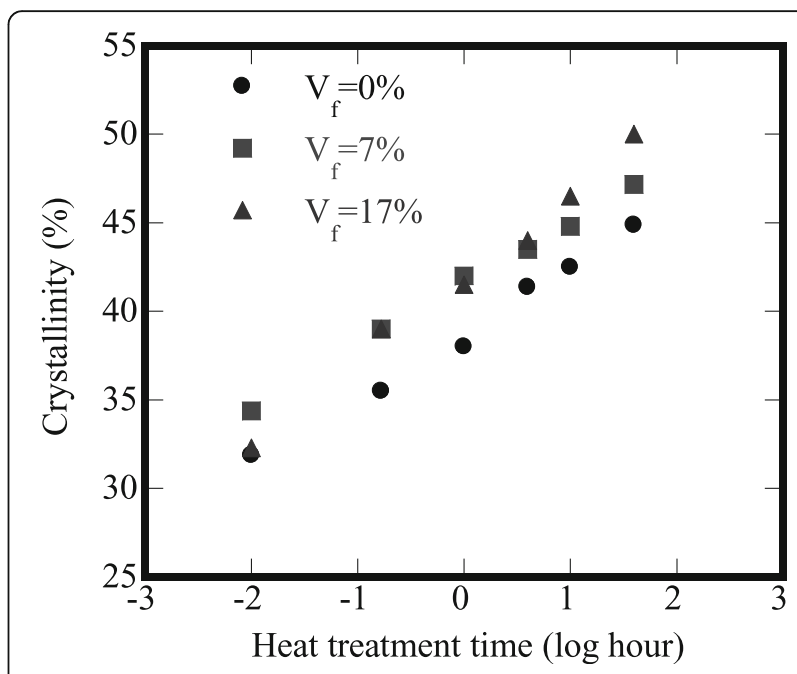

Fig. 3 The dependence of the crystallinity of PA and GFRPA on the duration of heat treatment (heat-treatment temperature: $250^{\circ} \mathrm{C}$ ) 
$d$ : Composite density

$d_{f}$. Fiber density $\left(2.57 \mathrm{~kg} / \mathrm{m}^{3}\right)$

$V_{f}$. Fiber volume fraction

Three-point bending tests were performed using an Instron-type universal testing machine (TCM-5000C by MINEBEA Co., Ltd.). The cross-head speed was $0.5 \mathrm{~mm} / \mathrm{min}$ and the span length was $40 \mathrm{~mm}$.

Three-point bending creep tests were carried out in silicon oil using a temperature deflection under loading machine (HDT VSPT Tester S-3 M, TOYOSEIKI Co., Ltd.). The span length was $40 \mathrm{~mm}$. The applied loads represented $10 \%$ of the static bending strength as determined in the three-point bending tests $(3 \mathrm{MPa})$. The tests were performed at $40,50,60,70$ and $80{ }^{\circ} \mathrm{C}$ with a test time of $1000 \mathrm{~min}$. Struik (Struik 1978) recommended generating master curves solely from momentary creep data, i.e., from creep data such that $t_{\mathrm{t}} \leq t_{\mathrm{a}} / 10$, where $t_{\mathrm{t}}$ is the test time and $t_{\mathrm{a}}$ is the length of the aging treatment. Based on this recommendation, creep tests performed after heating for $t_{a}\left(10 \times t_{\mathrm{t}}\right)$ are called short-term tests. This method yields slightly different results from those obtained by physical aging. However, we do not need to consider the effects of physical aging during creep tests. Each testing condition has three to five specimens, and each data has the variation less than $5 \%$. In this study, we showed one typical data.

\section{Results and discussion}

\section{Mechanical properties of PA and GFRPA with controlled} crystallinity

Few papers consider the effects of both fiber volume fraction and crystallinity when estimating the mechanical properties of a material. Figure 4 shows the mechanical properties obtained from bending tests performed on each PA and GFRPA specimen. Both strength and modulus increased with increasing crystallinity and fiber volume fraction such that the materials' bending behavior changed from ductile to brittle.

\section{Effect of crystallinity on the creep behavior of PA and GFRPA}

Previous studies Sakai and Somiya (2006, 2009, 2011, 2012), Sakai et al. (2007, 2011a, 2011b, 2015) and Tanks et al. (2016) have detailed creep behavior as a function of time, temperature, fiber volume fraction, physical aging, and crystallinity. These reports discussed the application of the TTSP and proposed a master curve of creep compliance showing the effect of each influencing variable. In the current study, creep tests were performed at elevated temperatures to assess the effects of crystallinity on the creep behavior of PA and GFRPA.

To evaluate the effect of temperature on creep phenomena, creep compliance curves were generated at each test temperature. The creep compliance curves for PA (crystallinity: $X=32 \%$ ) are presented in Fig. 5a, which shows that higher test temperatures and longer creep test durations resulted in higher creep compliance. A TTSP master curve of creep compliance is shown in Fig. 5b for a reference temperature of $40{ }^{\circ} \mathrm{C}$. The master curve was obtained by replacing the real-time $t$ for each shifted curve with the physical time $t^{\prime}$ at the reference temperature $T_{0}$. The amount that each individual curve needed to shift to create the master curve is the time-temperature shift factor. Shift factors for PA are plotted as an Arrhenius-type plot in Fig. 6. This curve is a straight line at temperatures above $40{ }^{\circ} \mathrm{C}$, indicating that creep phenomena comply with the TTSP in Arrhenius mode. Specimens of PA with other degrees of crystallinity and GFRPA exhibited the same trends as those in Figs. 5 and 6.

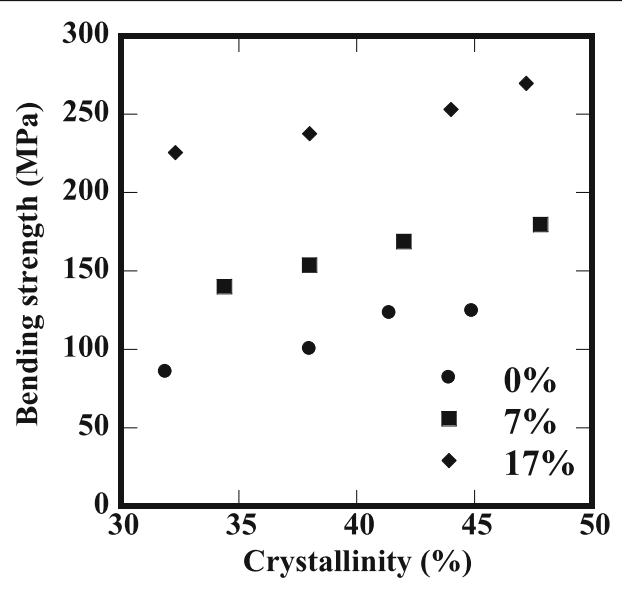

(a) Static Bending Strength

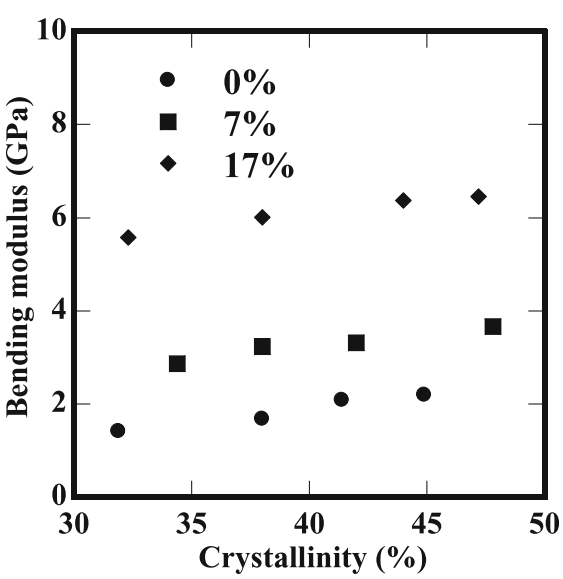

(b) Bending Modulus

Fig. 4 Crystallinity and fiber volume fraction dependency on (a) static bending strength and (b) bending modulus 


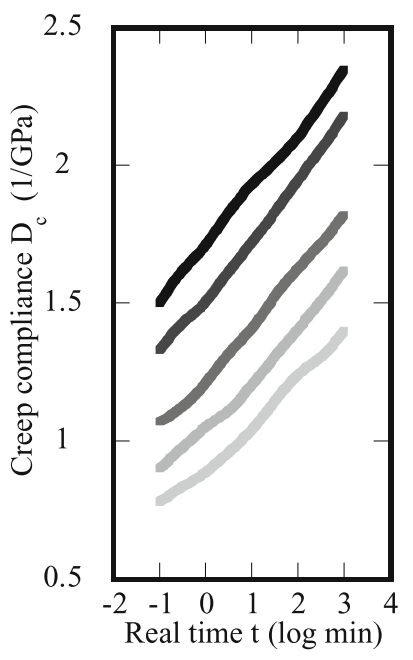

(a) Creep compliance Curves

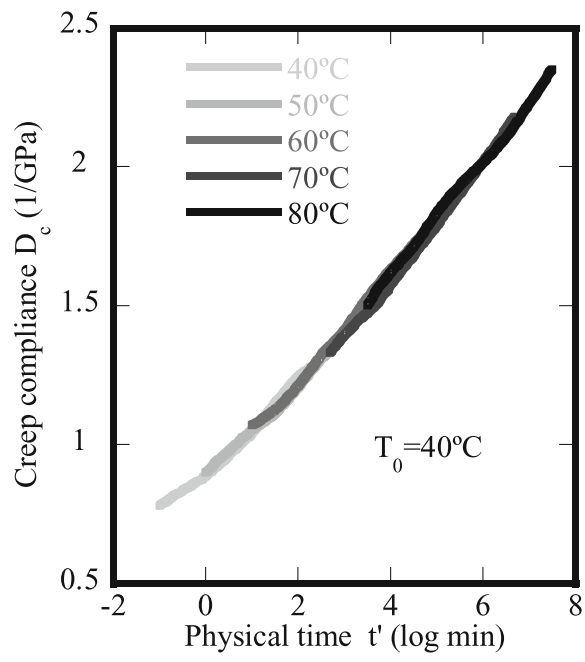

(b) Master curve

Fig. 5 a Creep compliance curves of PA and (b) the corresponding master curve $\left(V_{f}=0 \%, x=32 \%\right)$

To confirm the effects of crystallinity on creep behavior, Fig. 7a shows all of the master curves for PA. These data show that less crystallinity and longer creep test duration resulted in higher creep compliance. Master curves of crystallinity were generated by shifting individual curves horizontally and vertically until they overlapped with the reference curve. Figure $7 \mathrm{~b}$ shows the grand master curve for crystallinity. These data show that creep compliance curves of PA specimens with

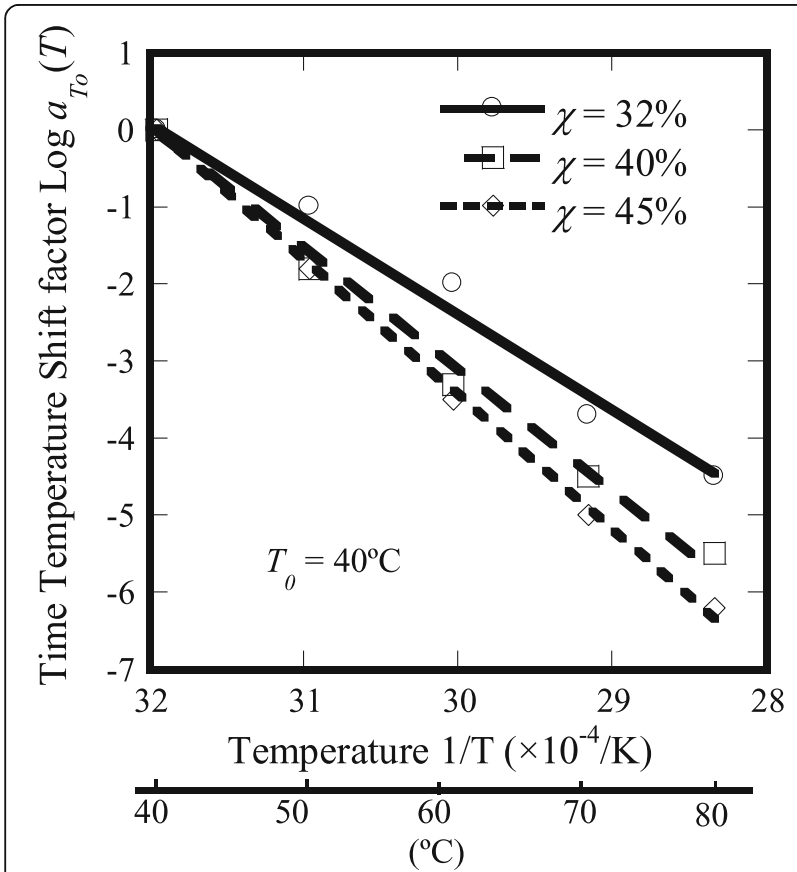

Fig. 6 Time-temperature shift factors of PA with various degrees of crystallinity different crystallinity are components of the grand master curve. Furthermore, the shape of the grand master curve is the same as those of creep compliance curves obtained from specimens of varying crystallinity. This shows that creep behavior was the same regardless of crystallinity. The shift factors along the horizontal and vertical directions are shown in Fig. 8. Vertical shifts show a change in modulus while horizontal shifts are indicative of time retardation effects. Crystalline domains delayed creep behavior. It is thought that this delay was due to decreasing molecular mobility with increasing crystallinity and consequent increases in viscosity. The same trends were observed with GFRPA, for which the creep deformation of materials with arbitrary crystallinity could be estimated using only the master curve and shift factors for each fiber volume fraction.

\section{The effects of fiber volume fraction on the creep behavior of PA and GFRPA}

Next, the effects of fiber volume fraction on creep behavior were estimated for PA and GFRPA specimens at a fixed crystallinity of $X=45 \%$ using the TTSP in Arrhenius mode. Master curves of PA and GFRPA were generated at elevated temperatures with TTSF of PA resin, as indicated in Fig. 9a, by shifting creep compliance curves horizontally until they overlapped. Figure 9a shows that lower fiber volume fractions and increased creep test duration yielded higher creep compliance. To confirm this effect, a grand master curve for fiber volume fraction, shown in Fig. 9b, was generated by shifting individual curves horizontally and vertically until they overlapped with a reference master curve at $V_{\mathrm{f}}=0 \%$. These data show that the creep behavior of GFRPA was the same as that of PA and that, furthermore, the creep 


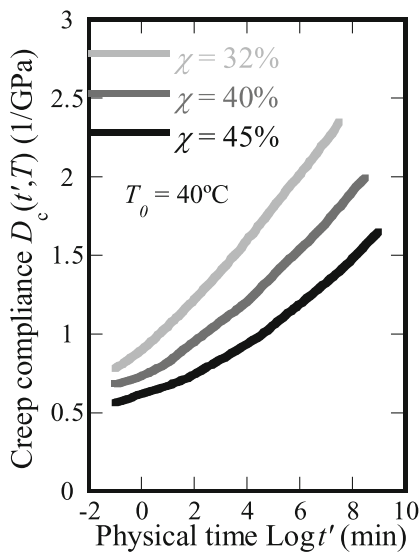

(a) Master curves

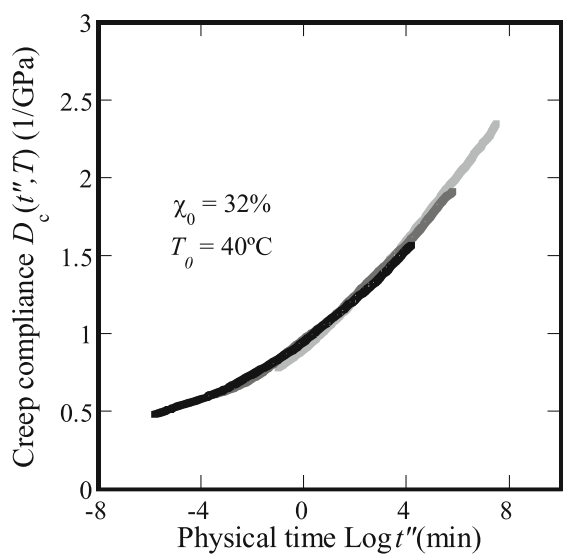

(b) Grand master curve

Fig. 7 a Master curves of creep compliance and (b) the corresponding grand master curve for the crystallinity of PA. (Reference curve: $X=32 \%, T_{0}=40{ }^{\circ} \mathrm{C}$ )

behaviors of PA and GFRPA depended on the behavior of the PA resin. The horizontal and vertical shift factors for fiber volume fraction are shown in Fig. 10. Vertical shifts were due to changes in modulus with increasing fiber content. Horizontal shifts were due to time retardation effects.

\section{Long-term estimation of creep deformation accounting} for the effects of crystallinity and fiber volume fraction Above, we discussed the separate influences of crystallinity and fiber volume fraction on creep behavior. Two effects were observed with both variables: changes in material modulus, and a retardation effect on time. We then tried to elucidate the relationship between the two variables. The shapes of the grand master curves in Figs. $7 \mathrm{~b}$ and $9 \mathrm{~b}$ are similar, so we tried to superimpose these into a single, great-grand master curve. To generate such a curve requires that a suitable reference curve

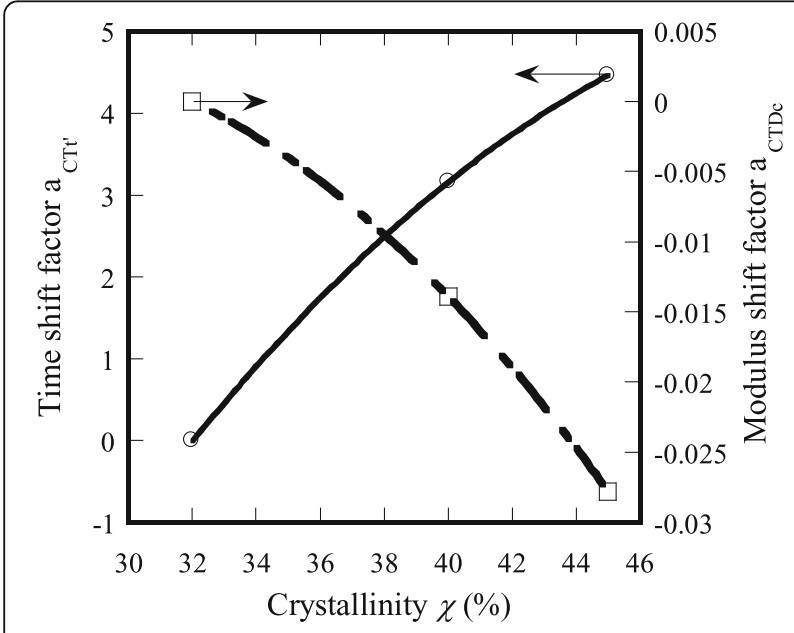

Fig. 8 Time and modulus shift factors for the crystallinity of PA be chosen. To do this, one must consider the relationship between the two grand master curves at $X=32 \%$ and $V_{\mathrm{f}}=0 \%$. The crystallinity of specimens used to generate the grand master curve for fiber volume fraction was $X=45 \%$. This curve was then shifted both horizontally and vertically, using the modulus and time shift factors for crystallinity, to create a grand master curve for crystallinity. Thus, we obtained the great-grand master curve shown in Fig. 11. The great-grand master curve is smooth, indicating that the effects of crystallinity and fiber volume fraction on creep behavior were similar. Furthermore, these data indicate that creep behavior can be controlled by adjusting the crystallinity and/or fiber volume fraction in accordance with the great-grand master curve and associated shift factors.

\section{Estimation of creep deformation}

Creep deformation under the influence of different variables can be estimated using only the great-grand master curve and associated shift factors. First, however, one must obtain an approximate equation of the master curve. An approximate equation, determined through a Prony series by Schapery (Schapery 1969; Schapery 1997; Lou and Schapery 1971), is shown in Eq. (4).

$$
D_{c}(t)=C_{e}+\sum_{i=1}^{N} C_{i}\left(1-e^{\frac{-t}{t_{i}}}\right)
$$

$C_{\mathrm{e}}$ : initial creep compliance, $C_{\mathrm{i}}$ : relaxation modulus, $\mathrm{\tau}_{\mathrm{i}}$ : relaxation time

Creep deformation can be estimated using Eq. (4). However, the data used to generate the great-grand master curve in this study were better fitted by Eq. (5), which is the same equation as that representing the Maxwell model. Despite the good fit with the experimental data, the Maxwell model is not applicable since 


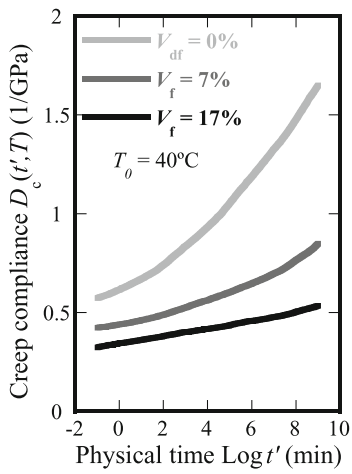

(a) Master curves

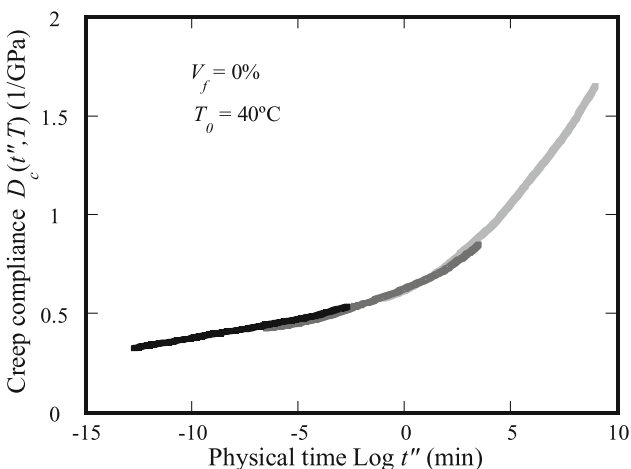

(b) Grand master curve

Fig. 9 a Master curves and (b) grand master curve for fiber volume fraction in PA and GFRPA. (Reference curve: $V_{f}=0 \%, T_{0}=40{ }^{\circ} \mathrm{C}$ )

it does not have any physical meaning pertaining to creep functions.

$$
D_{c}(t)=C_{e}+C_{1} \exp \left(\frac{-t}{\tau_{1}}\right)
$$

To estimate creep behavior, the effects of variables that influence shift factors were built into Eq. (1). The shift factors were multiplied by the test duration, $t$, since they exhibited retardation effects on time. Equation (6) calculates creep compliance taking into account the effects of time, temperature, and fiber volume fraction.

$$
D_{C}\left(t, T, V_{f}\right)=D_{C}\left(t \times a_{T R} \times a_{T t^{\prime}}\right)+a_{T D_{C}}
$$

$\mathrm{a}_{\mathrm{TR}}$ : Time-temperature shift factor,

$\mathrm{a}_{\mathrm{Tt}}$ : Time shift factor for fiber content,

$\mathrm{a}_{\mathrm{TDC}}$ : Modulus shift factor for fiber content,

$V_{\mathrm{f}}$ : Fiber volume fraction

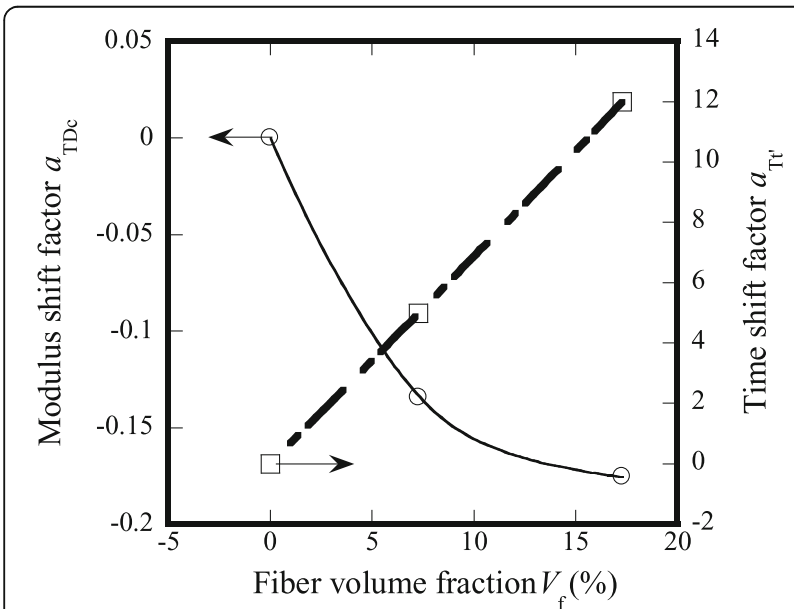

Fig. 10 Time and modulus shift factors for the fiber volume fraction of GFRPA
Equation (7) calculates creep compliance taking into account the effects of time, temperature, and crystallinity.

$$
D_{C}(t, T, C)=D_{C}\left(t \times a_{C T R} \times a_{c T t^{\prime}}\right)+a_{c T D_{C}}
$$

$a_{\mathrm{CTR}}$ : Time shift factor for crystallinity

$a_{\text {cTDc: }}$ Modulus shift factor for crystallinity

These equations show that creep analyses incorporating the great-grand master curve equation and shift factors for each of the influencing variables are useful for estimating creep behaviors. In addition, the suitability of

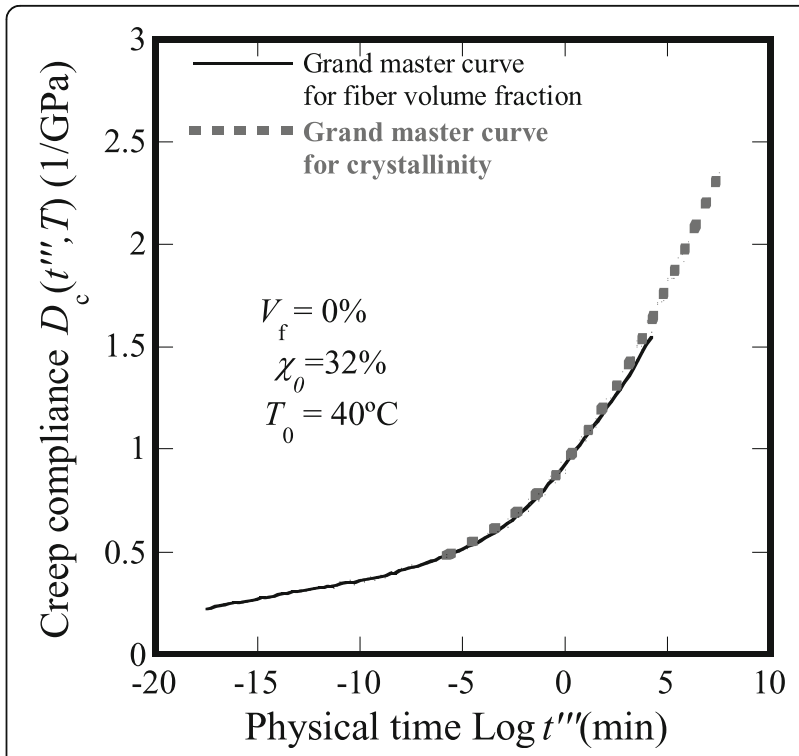

Fig. 11 Great-grand master curve obtained from grand master curves for crystallinity and fiber volume fraction of PA and GFRPA 
the TTSP in these analyses was validated by the observed effects of fiber volume fraction and crystallinity.

Creep deformation under arbitrary conditions can be estimated using only the great-grand master curve and associated shift factors, as shown in the block diagram of Fig. 12. The process for estimating behaviors is the reverse procedure of creating a great-grand master curve. Experimental values and estimated values for GFRPA $\left(V_{\mathrm{f}}=7 \%, \mathrm{X}=34 \%\right)$ are compared in Fig. 13. The test conditions were $50{ }^{\circ} \mathrm{C}$ with a creep time of $1000 \mathrm{~min}$ and $14 \mathrm{MPa}$ of applied stress. Note that the estimated data are in agreement with the experimental data. Of course, there is some difference between estimated and experimental data. Usually, experimental data has a dispersion as $5 \sim 10 \%$. Considering this dispersion, it can be said that our method can estimate long term creep behavior.

This study proposes a new means of estimating material properties based on the application of the timetemperature superposition principle, taking into account the effects of fiber volume fraction and crystallinity. We also showed that our estimates of creep deformation fitted well with experimental results. Based on these findings, it should be possible to control the creep deformation of a polymer material or fiber composite by controlling the fiber volume fraction and crystallinity.

\section{Conclusions}

A method for estimating creep deformation taking into account the effects of influencing variables was developed. The time-temperature superposition principle (TTSP) was applied to the effects of the fiber volume fraction and crystallinity. Grand master curves for crystallinity and fiber volume fraction were obtained by shifting the corresponding master curves. Time and

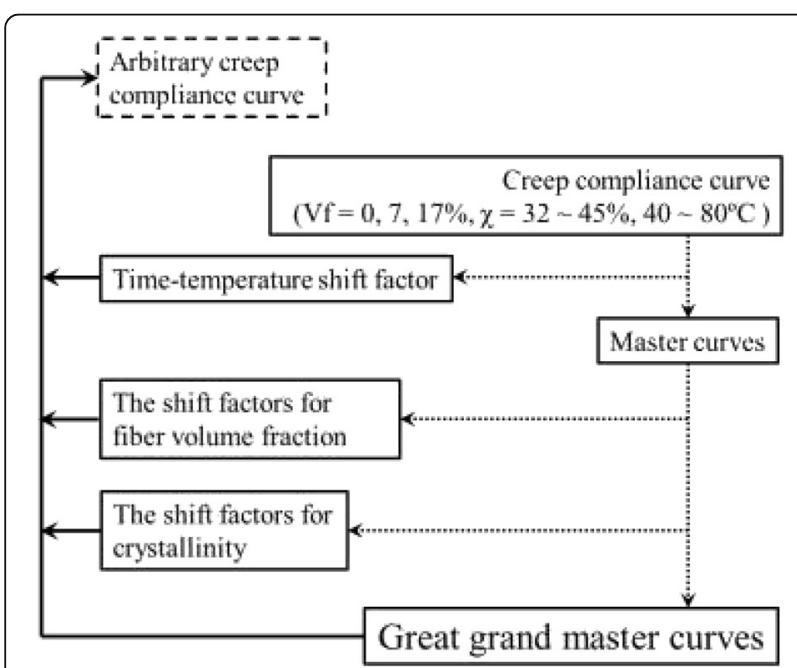

Fig. 12 Block diagram for the estimation of creep compliance under arbitrary conditions

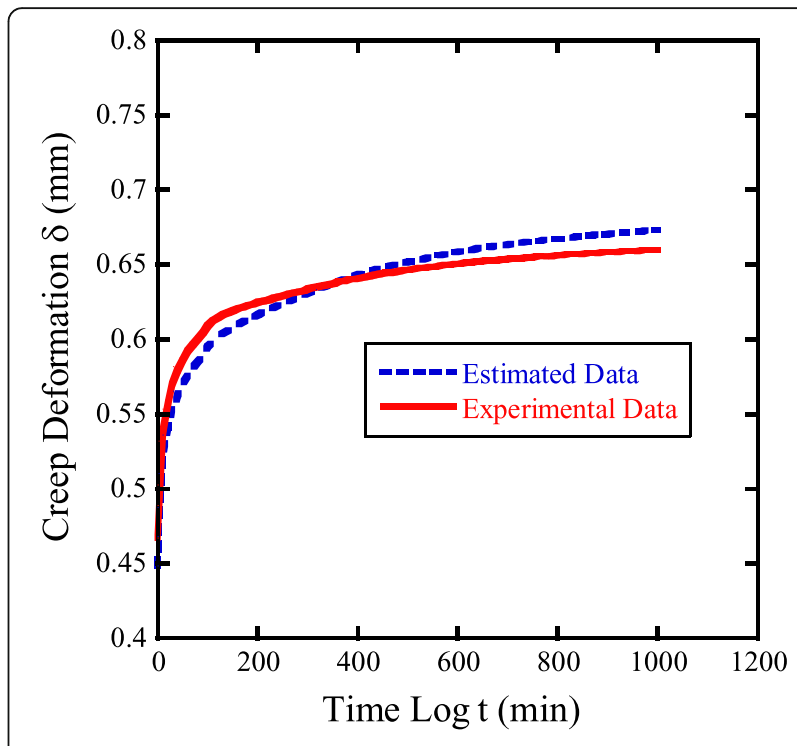

Fig. 13 Experimental and estimated values of GFRPA creep deformation

modulus shift factors for crystallinity and fiber volume fraction showed the effect of modulus on specimen properties and the retardation effect of creep behavior. This study demonstrates that the creep behaviors of fiber-reinforced plastics can be estimated using these shift factors and a great-grand master curve. This method yielded estimates of creep deformation that fitted well with experimental results. Based on our findings, it should be possible to control creep deformation in PA and GFRPA by controlling the fiber volume fraction and the crystallinity of the matrix material.

\section{Abbreviations}

GFRPA: Glass fiber reinforced polyamide; PA: Polyamide; TTSP: Timetemperature superposition principle

Availability of data and materials

Data sharing not applicable to this article as no datasets were generated or analysed during the current study.

Authors' contributions

TS analyzed data and wrote this manuscript. YH carried out all of experiment. SS conceived of the study, and participated in its design and coordination and helped to draft the manuscript. All authors read and approved the final manuscript.

Ethics approval and consent to participate

Not applicable.

\section{Consent for publication}

Author agrees to publication.

Competing interests

The authors declare that they have no competing interests.

\section{Publisher's Note}

Springer Nature remains neutral with regard to jurisdictional claims in published maps and institutional affiliations. 


\section{Author details}

Graduate School of Science and Engineering, Saitama University, 255

Shimo-Okubo, Sakura-ku, Saitama-shi, Saitama 338-8570, Japan. ${ }^{2}$ Department of Mechanical Engineering, Keio University, 3-14-1, Hiyoshi, Yokohamashi, Kanagawa 223-8522, Japan.

Received: 13 April 2018 Accepted: 21 September 2018

Published online: 29 September 2018

\section{References}

Brandrup J, Immergut EH, Grulke EA, (2003). Polymer Handbook fourth edition, V/ 124-V/126. Wiley, New York

Cai H, Nakada M, Miyano Y (2013) Simplified determination of long-term viscoelastic behavior of amorphous resin. Mech Time Dependent Mater 17:137-146

Chen M (1998) Crystallinity of isothermally and nonisothermally crystallized poly(ether ether ketone) composites. Polym Compos 19(6):689-697

Chiang WY, Lo MS (1987) Cooling and annealing properties of copolymer-type polyacetals and its crystallization behavior. J Appl Polym Sci 34(5):1997-2023

Creus GJ (2015) On the ageing of polymers and the time-shifting procedure. Mater Werkst 46:498-504

Ferry JD (1950) Mechanical properties of substances of high molecular weight; VI. Dispersion in concentrated polymer solutions and its dependence on temperature and concentration. J Amer Chem Soc 72:3746

Giannopoulos I, Burgoyne C (2012) Accelerated and real-time creep and creeprupture results for aramid fibers. J Appl Polym Sci 125:3856-3870

Lou YC, Schapery RA (1971) Visco-elastic characterization of a non-linear fiberreinforced plastic. J Compos Mater 5:208-234

Nakada M, Miyano Y, Cai H, Kasamori M (2011) Prediction of long-term viscoelastic behavior of amorphous resin based on the time-temperature superposition principle. Mech Time Dependent Mater 15:309-316

Oseli A, Aulova A, Gergesova M, Emri I (2016) Time-temperature superposition in linear and non-linear domain. Mater Today Proc 3:1118-1123

Sakai T, Okabe K, Yoneyama S (2011a) Effect of powder contents on viscoelastic behavior of glass powder filled epoxy resin. J Japanese Soc Exp Mech 11(Special Issue):187-191

Sakai T, Somiya S (2006) Estimating creep deformation of glass-fiber-reinforced polycarbonate. Mech Time Dependent Mater 10(3):185-199

Sakai T, Somiya S (2009) Effect of thermal history on the creep behavior of polycarbonate. J Solid Mech Mater Eng 3(11):1193-1201

Sakai T, Somiya S (2011) Analysis of creep behavior in thermoplastics based on visco-elastic theory. Mech Time Dependent Mater 15(3):293-308

Sakai T, Somiya S (2012) Estimating the creep behavior of polycarbonate with changes in temperature and aging time. Mech Time Dependent Mater 16(3):241-249

Sakai T, Tao T, Somiya S (2007) Viscoelasticity of shape memory polymer: polyurethane series DiARY ${ }^{\oplus}$. J Solid Mech Mater Eng 1(4):480-489

Sakai T, Tao T, Somiya S (2015) Estimation of creep and recovery behavior of a shape memory polymer. Mech Time Dependent Mater 19:569-579

Sakai T, Gushiken T, Koyanagi J, Rios-Soberanis R, Masuko T, Matsushima S, Kobayashi S, Yoneyama S (2011b) Effect of viscoelastic behavior on electroconductivity of recycled activated carbon composites. Appl Mech Mater 70:231-236

Schapery RA (1969) On the characterization of nonlinear visco-elastic materials. Polym Eng Sci 9(4):295-310

Schapery RA (1997) Nonlinear Visco-elastic and Viscoplastic constitutive equations based on thermodynamics. Mech Time Dependent Mater 1:209-240

Schwarzl F, Staverman AJ (1952) Time-temperature dependence of linear viscoelastic behavior. J Appl Phys 23:838

Struik L.C.E., (1978) Physical aging in amorphous and other materials, Elsevier Scientific Publishing Co., New York

Sukhanova T, Matveeva G, Vylegzhanina M (2004) Morphology and properties of poly(oxymethylene) engineering plastics. Macromol Symp 214:135-145

Tanks J, Rader K, Sharp S, Sakai T (2016) Accelerated creep and creep-rupture testing of carbon fiber laminates using the stepped isostress method. Compos Struct 159:455-462

\section{Submit your manuscript to a SpringerOpen ${ }^{\circ}$ journal and benefit from:}

- Convenient online submission

- Rigorous peer review

- Open access: articles freely available online

- High visibility within the field

- Retaining the copyright to your article

Submit your next manuscript at $\boldsymbol{\nabla}$ springeropen.com 